\section{Dr. Vicente Izquierdo Sanfuentes: pionero de la medicina, la biología experimental y la entomología chilenas}

\section{Vicente Izquierdo Sanfuentes, MD: A pioneer of Chilean medicine, experimental biology and entomology}

\section{Señor Editor,}

Con atención leí el interesante trabajo sobre el Dr. Vicente Izquierdo, ilustre médico y científico chileno, publicado en la Revista Médica de Chile ${ }^{1}$, de la cual también fue Director ${ }^{2}$. Los autores de este artículo efectúan una detallada descripción sobre el inicio de la biología celular chilena, siendo Izquierdo uno de sus protagonistas $^{1}$. En consonancia con esto, es importante también difundir las inclinaciones naturalistas de este prohombre de la ciencia chilena. Así, el objetivo de esta Carta al Editor es destacar a Vicente Izquierdo como pionero de la medicina, de biología experimental y la entomología chilena.

Vicente Izquierdo Sanfuentes (1850-1926; Figura 1A) se formó académicamente en Europa, específicamente en Alemania, donde completó su formación médica y científica ${ }^{1,2}$. Fue discípulo de Wilhelm Waldeyer (1836-1921), destacado anatomista, histólogo y patólogo alemán, defensor de la «Doctrina de la Neurona». Al regresar a Chile, Izquierdo revalidó su título de Médico Cirujano y fue nombrado Profesor de Histología en la Universidad de Chile² (Figura 1B).
Destacó como docente preocupado por los estudiantes, por las explicaciones que podía darles durante el trabajo con el microscopio y por la meticulosidad de sus dibujos en las clases ${ }^{3}$. Finalizada la Guerra del Pacífico (1879-1884), Izquierdo publicó un artículo en la prestigiosa revista alemana Archivos Virchow, investigación que trató sobre las características fisiopatológicas de la enfermedad de la verruga peruana («Spaltpilze bei der "Verruga peruana"»), en la cual se había interesado por haber aquejado a soldados chilenos durante la Guerra ${ }^{2,4}$. Actualmente se sabe que ésta es causada por Bartonella bacilliformis, bacteria que puede estar presente en la mosca hematófaga Lutzomyia verrucarrum. El trabajo de Izquierdo es relevante por su enfoque histopatológico, por describir las semejanzas de la verruga peruana con los sarcomas y por animar a Daniel Carrión (1857-1885), «Mártir de la Medicina Peruana», a realizar el experimento que demostró, a costa de su vida, que la verruga peruana y la fiebre de La Oroya son la misma patología ${ }^{2,4}$.

Debido a que su familia poseía propiedades con amplios terrenos, Vicente Izquierdo cultivó desde pequeño un especial sentido de observación de la naturaleza ${ }^{1}$. Su interés naturalista se demuestra en 1895 al publicar en los Anales de la Universidad de Chile el artículo «Notas sobre los lepidópteros de Chile» ${ }^{2}$, trabajo en el área de entomología en el cual efectuó una acabada descripción de diversas mariposas con detalladas láminas dibujadas. Ese mismo año publica «Sobre los líquidos arrojados por los insectos para defenderse de sus enemigos» en las Actes de la Societé Scientifique du Chili. Posteriormente publica el En- 


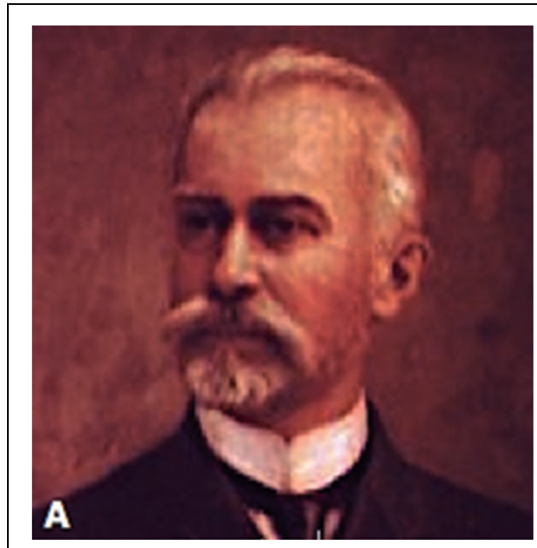

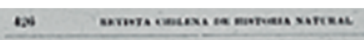

Observaciones sobre is

Biologia de ia Polgthisana comondsi, zall (7) mas.

D. Vicente izQuickoo.

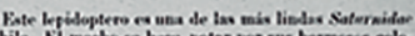

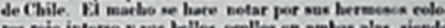

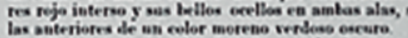

Sus antenus net forntemente jectinada. 5 provistas

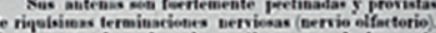

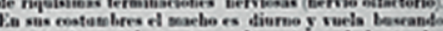

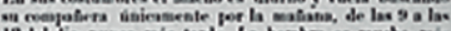
12 del dis, nutea mis tarde ta hembra es merbs mi.

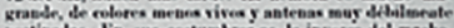

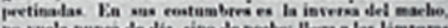
no vuela nusea de lis, sine de noche, lloga a las limpara.

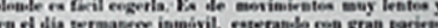
is oer vieitala per alguin macho.

I rote rojerto nsestra esjerie se diferencia de 1

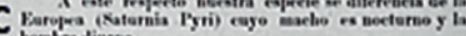
bentradiuma.
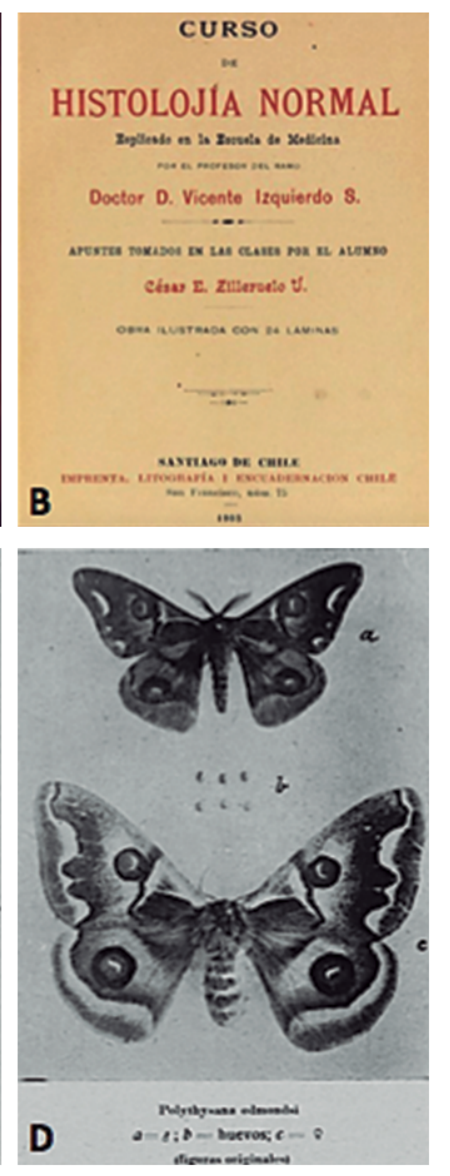

Figura 1. Obra del doctor Vicente Izquierdo. A. Fue Diputado (1885-1888) por Santiago (archivo Biblioteca del Congreso Nacional de Chile). B. Texto de Histología basado en sus clases (archivo Biblioteca Nacional de Chile). C. Portada del artículo sobre substancias volátiles en mariposas. D. Polythysana edmondsi, la mariposa estudiada (C y D adaptado de Izquierdo ${ }^{5}$ ). sayo sobre los Protozoos de las Aguas Dulces de Chile (1906), investigación que, según el Dr. Joaquín Luco (1913-2002) médico, neurobiólogo y Premio Nacional de Ciencias, fue bien considerada por Waldeyer: " $i$ Tenemos por acaso nosotros algo completo sobre los protozoos de Alemania?...Esto lo ha hecho usted para Chile y se le tendrá que agradecer» ${ }^{3}$. Más tarde, un aporte trascendental de Izquierdo a la biología experimental se desarrollaría nuevamente en entomología (Figura 1C): Entre 1919-1921, en un parque cercano a la Estación de Nos (San Bernardo), encerró mariposas hembras en celo en una campana de tela de alambre, sobre la que comenzaron a agolparse los machos. De esto concluyó que las hembras generaban una substancia volátil (Figura 1D): «...después que se ha colocado una hembra virgen, en cualquier lugar, la atmósfera tiene que impregnarse de algún efluvio, hasta muchos metros de distancia, que es instantáneamente percibido por los machos» ${ }^{5}$. Estos experimentos de conducta sexual de mariposas develaron que en su reproducción actuaría un quimiotropismo positivo por una substancia sintetizada por la hembra, estudios que no fueron adecuadamente reconocidos. Sin embargo, los doctores Joaquín Luco y Ricardo CruzCoke (1925-2016) destacan que Izquierdo se adelantó unos treinta años en demostrar la existencia de las feromonas ${ }^{2,3}$. De hecho, el concepto «feromona» fue propuesto recién en 1959 como «substancias que son secretadas hacia el exterior por un individuo y recibidas por un segundo individuo de la misma especie, en el cual ellas originan una reacción específica, por ejemplo, una conducta definida o un proceso de desarrollo» ${ }^{6}$.

Se concluye que la obra del Dr. Vicente Izquierdo permitió que la biología chilena evolucionase desde un enfoque naturalista a uno experimental. Su obra debe ser difundida como parte del acervo cultural científico y su legado debiese ser estudiado como parte de las humanidades médicas y de la historia de las ciencias 
biológicas y de la salud chilena. Con justa razón podemos considerar a Vicente Izquierdo como un pionero, una de las grandes figuras de las ciencias médicas y biológicas chilenas.

Manuel E. Cortés ${ }^{1,2, a}$ ${ }^{1}$ Departamento de Ciencias Pedagógicas y Programa Doctorado en Educación, Universidad Bernardo O'Higgins (UBO), Santiago, Chile. ${ }^{2}$ Programa Magíster en Ciencias Químico Biológicas, UBO, Chile.

${ }^{a}$ Biólogo, Profesor de Química, Ingeniero en Prevención de Riesgos, M.Sc., Ph.D.

\section{Referencias}

1. Sabaj V, Osorio CG. El arribo de la teoría celular a Chile: Dr. Vicente Izquierdo Sanfuentes. Rev Med Chile 2020; 148: 528-34.
2. Cruz-Coke R. Historia de la medicina chilena. Santiago: Editorial Andrés Bello; 1985.

3. Luco JV. El Albor de la Biología en Chile. Una trova personal. Bol Esc Med UC 1982; 28: 71-85.

4. Salinas D. La verruga peruana: investigación histopatológica realizada por Chile en el siglo XIX. Rev Peru Med Exp Salud Publica 2014; 31 (3): 601-10.

5. Izquierdo V. Observaciones sobre la Biología de Polythysana edmondsi. Rev Chil Hist Nat 1921; 25(1):426-32.

6. Karlson P, Lüscher M. 'Pheromones': a New Term for a Class of Biologically Active Substances. Nature 1959; 183 (4653): 55-6.

Correspondencia a:

Dr. Manuel E. Cortés

Decano Interino, Profesor Titular, Facultad de Educación, UBO.

C.P.8370993, Chile.

cortesmanuel@docente.ubo.cl 